\title{
Crowdfunding y audiovisual de proximidad. La economía colaborativa como instrumento de desarrollo sectorial
}

\author{
Basilio Cantalapiedra Nieto
}

RESUMEN: El objetivo de este trabajo es analizar cómo el crowdfunding aplicado a la financiación audiovisual, puede incentivar la generación de contenidos de proximidad y, apoyándose en el crowdsourcing, favorecer el desarrollo del sector audiovisual en zonas alejadas de los grandes centros de producción estatales. En un sector audiovisual como el actual, fragmentado en las audiencias y en continua evolución en cuanto a los modelos de negocio, se hace necesaria la evaluación de la idoneidad de unas estrategias de crowdfunding uniformizadas para todo tipo de productos. Igualmente, la generación de contenidos audiovisuales de proximidad dirigidos a espectadores unidos por lo geográfico y temático, puede encontrar una idónea vía de financiación y gestión a través de las plataformas de crowdfunding y de crowdsourcing. La aplicación del crowdfunding a los contenidos de proximidad debe adecuar los planteamientos del producto y las recompensas propuestas a los caracteres de dicha proximidad, mientras la práctica del crowdsourcing pone en relación a los agentes productores con el personal técnico y artístico cercano, favoreciendo el establecimiento de redes de trabajo potencialmente estables que sirvan de instrumento para el desarrollo del sector audiovisual local. Para ello se ha procedido al estudio de dos de las plataformas de crowdfunding más representativas a nivel estatal, Verkami y Lánzanos. El trabajo se centra en la tipología de los proyectos audiovisuales de proximidad, su volumen presupuestario y los aspectos utilizados tanto para su descripción como para el establecimiento de las recompensas.

PALABRAS CLAVE: Audiovisual, Crowdfunding, Crowdsourcing, Proximidad.

CLAVES ECONLIT: D2, L8, Z1.

Cómo citar este artículo / How to cite this article: CANTALAPIEDRA, B. (2019): "Crowdfunding y audiovisual de proximidad. La economía colaborativa como instrumento de desarrollo sectorial", CIRIEC-España, Revista de Economía Pública, Social y Cooperativa, 95, 257-288. DOI: 10.7203/CIRIEC-E.95.9095.

Correspondencia: Basilio Cantalapiedra Nieto, Doctor por la Universidad de Burgos, Facultad de Humanidades

y Comunicación, Calle Parralillos s/n, Despacho 049, 09001 Burgos.

E-mail contacto: bcantalapiedra@ubu.es. 


\section{EXPANDED ABSTRACT}

\section{Crowdfunding and proximity audiovisual. Collaborative economy as an instrument of sectorial development}

\section{Objectives}

The Spanish audiovisual sector is focused around two major production centres, Madrid and Barcelona, although its potential audience are spread throughout the Spanish territory. The creation of an industrial fabric outside these centres depends on the individual initiative of local production companies, although it is difficult to maintain a continuous activity. The search for thematic differentiation leads to the production of proximity content, reducing management costs by taking advantage of the options provided by the Internet to distribute content.

This work aims to analyse the way crowdfunding applied to financing audiovisual projects can help proximity content and, based on crowdsourcing, promote the development of audiovisual sector in areas far from important state production centres. The prosumer role assumed by users can encourage crowdfunding platforms to operate as a professional social network that facilitates the development of stable work teams, enabling the creation of the necessary audiovisual industrial fabric in territories with no tradition in the sector.

Likewise, the purpose is to study the effectiveness of crowdfunding campaigns aimed at the audiovisual sector, analysing their features in relation to the professional sphere. In current audiovisual sector, divided into audiences and continuously evolving concerning business models, it is necessary to evaluate the suitability of any crowdfunding strategies standard for all kind of products. In the same way, making proximity audiovisual content for spectators, connected by geographic and thematic aspects, can find the appropriate way of financing and managing through crowdfunding and crowdsourcing platforms.

\section{Design/methodology/approach}

The object of the study was the audiovisual projects used by the Verkami and Lánzanos crowdfunding platforms to plan their financing campaigns. Both have big importance at state level as they cover needs of the sector. They excel in their length of service, volume and success rate and they include a specific section for audiovisual products, working according to the rewards model. 
A preliminary study of sectoral and geographical data was carried out, focusing on the territorial dispersion of audiovisual production and consumption, in order to tackle the issue of proximity content. Subsequently, the projects analysed for both platforms were divided into two large groups: documentaries on local subjects and feature-length fiction films developed by promoters not based in the two large state production centres. The study was carried out during the month of July 2016 , on campaigns for which the deadline for receiving contributions had expired in that period. The analysis includes projects that were unsuccessful in reaching their funding target. Finally, conclusions have been drawn.

\section{Results/Research limitations/implications}

The campaigns analysed have a fundamental impact on emotions. Their description is based on highlighting the social and human interest of the main characters and the space portrayed audiovisually. The subject matter is the descriptive axis of the project, but, compared to the information that a professional production dossier would provide, essential aspects such as synopsis, locations, shooting plan and financing or budget of the project are avoided. In many cases it not mentioned whether it is a feature film or a short film, even though the way to face any project depends fundamentally on this question, defining, also in terms of budget, the real difficulty for a project and its feasibility. It is also important to know the stage the product is in when the campaign is called, this fact is usually provided, although not clearly enough.

The estimated cost of the project and the percentage still to be covered are barely described. For this reason, the specific financing objective of each project does not allow definitive conclusions to be drawn on the real effectiveness of the campaigns in each proposal. The Official Budget tool would provide a suitable model for quantifying and identifying the items for which funding is requested, and also for managing a coherent crowdfunding schedule.

The rewards offered are intended for patrons to feel important in the development of the product. The minimum and maximum contributions proposed follow the criterion of diversifying the options, generating multiple peaks in the final number of patrons, foreseeably local users as potential first spectators of the products.

The feature films studied do not reach the usual minimum figures of the sector, and it can be inferred that this behaviour is closer to amateurism than to the professional world. The failure rate is relatively high in these campaigns, not assuming the economic expenditure involved in audiovisual production.

The possibilities provided by the combination of a crowdfunding strategy with a crowdsourcing strategy, favouring the audiovisual professional activity of these areas, should be highlighted. The contributions of the patrons can be used for financing in exchange for rewards, but they could also cover the 
contribution with the professional experience from many users, who are capable of carrying out the specialised tasks required in teamwork such as audiovisual work.

There is a niche of action crucial to facilitate the promotion of a more stable professional activity, which can generate an industrial fabric within the sector, non-existent in many geographical areas.

\section{Practical conclusions and original value}

The technological evolution of the audiovisual sector requires a constant reconversion of the business model, including the financing process. Thus, crowdfunding takes advantage of the collaborative practices enabled by the Internet, encouraging users to participate in projects and become an active part of the product. Platforms such as Verkami or Lánzanos turn patrons into motors for audiovisual projects that are akin to them in terms of subject matter or geography. This means that the idea of proximity is used as an instrument for selling the project, defining also the target audience of the campaigns, turning them into a possible system of communication between local producers and users. Similarly, as in the crowdsourcing philosophy, these can contribute with their capacities for a better development of the project, even in a continuous way, with the final goal of laying the foundations of an audiovisual industrial fabric in areas where it does not exist.

The analysis of the campaigns on the Verkami and Lánzanos platforms allows us to conclude that the projects are maybe a bit unprofessional, which prevents us from taking full advantage of the possibilities offered by crowdfunding. Localised problems include the lack of information on the total budget, the destination of the funds or even the definition of the type of product (feature film or short film). There is also an excessive confidence in the predisposition of possible patrons, as well as a lack of delimitation of the same that would facilitate better structured campaigns. It is therefore inferred an overdimensioning of the real capacity of the promoter to undertake his product and an absence of realism on the economic needs of the same, achieving residual figures. The Official Budget should be used as a tool to plan financing through crowdfunding, segmenting the phases of preparation of the product and the campaigns located in them.

KEYWORDS: Audiovisual, Crowdfunding, Crowdsourcing, Proximity. 


\section{Introducción}

El audiovisual estatal se focaliza en dos grandes centros de producción, Madrid y Barcelona. Allí se concentran las sedes de la mayoría de productoras encargadas de generar contenidos, aunque sus potenciales consumidores, los espectadores, se reparten por todo el territorio español. El intento por crear un tejido industrial audiovisual fuera de estos focos, puede asirse a la esperanza de la acción de las televisiones autonómicas o a la iniciativa personal de las productoras de la zona. Pero las dificultades para poder desarrollar una actividad continuada son extremas. No existen proveedores establecidos, los técnicos y actores se ven obligados a dirigir su trabajo hacia los grandes centros de producción, y las estructuras de financiación no ofrecen seguridad en cuanto a su funcionamiento. Por ello, el intentar diferenciarse temáticamente de los productos estandarizados lleva a estos "artesanos de la producción" a aplicar su esfuerzo a generar contenidos de proximidad, no por localistas de menor interés, amortizando los costes propios de desplazamientos y su traslación económica en tiempo de gestión, aprovechando las posibilidades que ofrece Internet para distribuir los contenidos.

Aunque el público al que se dirigen los productos es obviamente menor en número, por la restricción geográfica y temática, está predispuesto a interesarse en los proyectos por las cuestiones próximas de las que hablan los contenidos. Dicha predisposición y la proactividad con la que atienden a los temas que son de su interés, es una característica que puede y debe aprovecharse con las nuevas modalidades de financiación que las nuevas tecnologías ofrecen. Así, estrategias como el crowdsourcing y el crowdfunding pueden encontrar su "pareja de baile" idónea en este tipo de producciones audiovisuales de proximidad, siempre que el tamaño del contenido se adecúe a lo que las plataformas permiten. De igual forma pueden actuar como una red social profesional que facilite el encuentro y desarrollo de equipos humanos de trabajo, repitiendo este modelo de financiación en proyectos distintos y consecutivos, en pos de generar un pequeño, aunque suficiente, tejido industrial audiovisual en áreas geográficas sin tradición en el sector.

\section{El crowdfunding como modelo de financiación audiovisual}

El desarrollo de las tecnologías de la información y comunicación, en un periodo de crisis económica, combinado con una nueva mentalidad social y económica, han provocado el camino hacia una cultura basada en la producción colaborativa o en los recursos compartidos (Correcher Mato, 2017). 
Dicho estado de crisis, asumido como modus vivendi por el sector audiovisual, encuentra en las prácticas de innovación social un posible remedio, incrementándose su interés por la coyuntura de crisis económica y financiera que ha marcado la presente década (Hernández-Ascano, Tirado Valencia y Ariza-Montes, 2016). Podría decirse que si estas prácticas surgen en parte para aplacar los efectos de la crisis puntual en cualquier sector, la constancia de dicha crisis en el audiovisual encuentra una solución para solventar, al menos parcialmente, su perenne estado crítico. Las definiciones sobre innovación social coinciden en situar el inicio del proceso innovador en "una necesidad no satisfecha junto con la intención de satisfacerla", convirtiéndose la innovación en motor de los procesos de desarrollo, evolución y cambio social, dando respuesta a una demanda socialmente definida, corrigiendo los posibles desajustes del entorno (Hernández-Ascano et al., 2016:170).

El crowdfunding es uno de los modelos de innovación social, junto a fenómenos como el business angels 0 el mecenazgo y micromecenazgo entre otros, como procedimientos que surgen para cubrir necesidades de financiación basándose en el apoyo de los ciudadanos, en un contexto económico que precisa incentivar nuevas formas de financiación, alternativas a las tradicionales, que fomentan además el espíritu emprendedor. El crowdfunding tiene cabida dentro de la noción de innovación social operando como una novedosa forma de financiar un proyecto, obteniendo fondos que de otra manera no se hubieran conseguido, en una época que conjuga la restricción del crédito por las vías tradicionales con el avance de las comunidades basadas en Internet (Soto Moya, 2017). El componente colectivo de este modelo se basa en la idea de economía colaborativa, la cual hace referencia "a los nuevos sistemas de producción y consumo de bienes y servicios surgidos gracias a los avances de la tecnología de la información para intercambiar y compartir dichos bienes y/o servicios a través de plataformas digitales" (Alfonso, 2016:231). No existe una definición institucionalizada de economía colaborativa, ya que se trata de una realidad en formación, con contornos difusos y que puede identificarse tanto como modelo de consumo o de negocio. Si se incide en el último puede entenderse como "una variante de la economía digital que utiliza esquemas similares, que busca como fin la obtención de recursos y no la optimización y compartición de los mismos", en la que si el principal fin de la prestación de servicios se asocia a la consecución de beneficios, se hablaría de economía colaborativa, mientras que si el objetivo es compartir u optimizar recursos, se situaría en el ámbito del consumo colaborativo (Correcher Mato, 2017:259). De entre las actividades básicas de la economía colaborativa pueden distinguirse el consumo colaborativo, la producción colaborativa en la que se colabora en el diseño, producción o distribución de bienes. A estas se añaden el aprendizaje colaborativo y finalmente, la que tiene que ver con las finanzas colaborativas o servicios de financiación, préstamo 0 inversión que se prestan al margen de las entidades financieras tradicionales. Es el caso del crowdfunding (Alfonso, 2016).

El generalizado uso de Internet obliga a la adecuación de la actividad económica para aprovechar las posibilidades que ofrece, y el sector audiovisual incluso más por el peso de lo tecnológico y el hecho de que las prácticas tradicionales se vean superadas por el cambio de actitud del espectador. Esto es notorio en la distribución y exhibición de contenidos, ya que el consumo audiovisual vira de la anterior asistencia masiva a salas de cine al actual modelo en que los espectadores acceden a los contenidos 
mediante múltiples pantallas. Internet permite también que las redes sociales formen un entramado de usuarios que comparten gustos y opiniones, retroalimentándose sobre lo que han visto, sus inquietudes o su necesidad de nuevos proyectos que desarrollen las tramas de las que son fans, participando incluso en su creación mediante el fenómeno transmedia. Esta realidad se ha convertido en una variable a manejar en la financiación de productos audiovisuales, y una opción emergente en este sentido, el crowdfunding, encuentra su marco operativo en la red. La interconexión entre los usuarios, permitida al demoler Internet las barreras físicas que les separan, cambia su manera de relacionarse y la dinámica empresarial. La distancia geográfica deja de ser un problema insalvable apareciendo nuevos modelos de trabajo que aprovechan la comunicación inmediata y en red. Internet, como medio de conexión principal de los colaboradores, puede permitir a los usuarios encontrarse en puntos geográficos distintos e incluso alejados entre sí (Sánchez Roger, 2015). Así el crowdsourcing irrumpe como práctica, externalizando una función realizada por un empleado de una empresa o institución, mediante una convocatoria abierta hecha a un grupo indefinido (y generalmente grande) de personas, que puede hacerse de manera colaborativa entre iguales (peer-production) o de forma individual (Howe, 2006). También puede definirse como un modelo estratégico capaz de aportar soluciones superiores en calidad y cantidad a las que pueden dar las formas tradicionales de negocio, proporcionadas por una multitud interesada y motivada de individuos (Brabham, 2008). El término se compone de los vocablos crowd y outsourcing, tomando el significado de externalizar determinadas funciones a un grupo de personas externas (Kleeman, Voß, y Rieder, 2008), apoyándose en la idea "wisdom of a crowd" (sabiduría de la multitud) propuesta por Surowiecki (2004). El espíritu colaborativo del crowdsourcing, se extiende a lo económico con el crowdfunding, por el que se convoca a los individuos de la comunidad a invertir no solo su tiempo y conocimientos, también su dinero. El crowdfunding es un democrático mecanismo basado en Internet, que utiliza elementos del mercado libre y el conocimiento colaborativo, para agrupar a las personas y comunidades en torno a una causa común, aunque frente a una cierta ciberutópica idea que lo sitúa como el paso hacia la sociedad globalizada que promueva la diversificación cultural y geográfica, acortando distancias y brechas (Brüntje y Gajda, 2016), tiene aún un largo camino por recorrer. Tomando las principales definiciones, algunas coinciden en identificar Internet como su medio principal de comunicación (Belleflamme, Lambert y Schwienbacher, 2010; Fiedler y Horsch, 2014; Lambert y Schwienbacher, 2010), incluso centrándolo en la web 2.0 (Wenzlaff, Gumpelmaier y Eisfeld-Reschke, 2012). Mediante convocatoria abierta (Belleflamme et al., 2010; Lambert y Schwienbacher, 2010; Tomczak y Brem, 2013) una empresa busca aprovisionarse de recursos financieros a cambio de alguna forma de recompensa y/o derecho a voto (Belleflamme et al., 2010; Lambert y Schwienbacher, 2010). Puede tratarse de una recompensa material o inmaterial (Wenzlaff et al., 2012), o monetaria o no (Voorbraak, 2011). La innovación del proyecto o idea de negocio financiable es un aspecto destacable para Fiedler y Horsch (2014), así como el concepto del micropago (Hemer, Schneider, Dornbusch, Frey, 2011) y la externalización del problema de la financiación frente al modelo tradicional (Tomczak y Brem, 2013). El posible carácter creativo de los proyectos también debe tenerse en cuenta (Wenzlaff et al., 2012). Al nivel estatal corporativo, se define como "un sistema de cooperación que permite a cualquier persona creadora de proyectos, reunir una suma de dinero entre muchas personas para apoyar una determinada iniciativa empresarial, cultural, social o deportiva" (SCF, 2014:4). El crowdfunding incluye tres partes interesadas: los promotores que buscan finan- 
ciación para sus proyectos, los patrocinadores dispuestos a respaldar un proyecto específico, y las plataformas de crowdfunding que actúan como intermediarios (Belleflamme, Lambert y Schwienbacher, 2014). Familia y amigos suelen ser un relevante grupo patrocinador de los proyectos. Los patrocinadores pueden motivarse a apoyar proyectos en los que tienen una relación emocional, familiar o de amistad. Quien emprende considera a los aportantes como personas afines a sus inquietudes y como los mejores prescriptores del proyecto, pues trabajan con el fin común del éxito (Soto Moya, 2017), aunque sea el emprendedor quien guía los esfuerzos de innovación, en pos del mismo (HernándezAscano et al., 2016). Otro motivo posible es la identificación regional, por la proximidad geográfica entre un promotor del proyecto y un patrocinador (Agrawal, Catalini y Goldfarb, 2011), ya que los inversores tendrían un sesgo local en la asignación del crédito (Lin y Viswanathan, 2016).

Todas las clasificaciones típicas se basan en el tipo de devolución, obviando cuestiones como las dimensiones de las plataformas. Pueden establecerse tres arquetipos genéricos de crowdfunding diferenciados por la propuesta de valor que persiguen, distinguiéndose los modelos basados en el hedonismo, altruismo y con fines de lucro (Haas, Blohm y Leimeister, 2014). El primero describe propuestas sobre proyectos innovadores y creativos, recibiendo los mecenas un rendimiento no monetario como recompensas o productos preordenados. El modelo altruista se enfoca a proyectos caritativos, prevaleciendo la donación como forma de apoyo, sin ninguna compensación. Los mecenas apoyan los proyectos por el bien común. El último se orienta a la búsqueda de beneficio, dirigiéndose a menudo a la financiación de nuevas empresas. A los patrocinadores se les ofrecen beneficios monetarios, como intereses o participaciones en los beneficios. Según la naturaleza del intercambio, el crowdfunding acoge la siguiente tipología (De Voldere y Zeqo, 2017):

- Donación: los donantes aportan pequeñas cantidades para cumplir con objetivos de financiación mayores sin recibir una contrapartida material o económica a cambio. Suele enfocarse a proyectos solidarios humanitarios.

- Recompensa: El mecenas hace una aportación con la expectativa de recibir una contraprestación o producto tangible, como compensación no dineraria asimilable a una preventa. Es habitual en el desarrollo de proyectos creativos.

- Inversión (Equity-based): El inversor recibe una participación en el negocio o compromisos sobre beneficios del mismo, como contraprestación a lo aportado.

- Préstamo (Peer-to-Peer lending): los prestamistas reciben lo prestado, junto a un tipo de interés previamente acordado, como contraprestación a lo aportado mediante una plataforma en línea. Este tipo opera para empresas y particulares, como préstamos comerciales y de consumo.

Las potencialidades del crowdfunding varían en función de los proyectos y las plataformas que los alojan. La recaudación de fondos es la principal, buscando superar una brecha en la etapa inicial de las nuevas empresas. Proporciona a las PYMES capital para financiar sus proyectos o permitirles realizar otros de cariz creativo, altruista, ecológico o social (Belleflamme et al., 2010), que frecuentemente reflejan nichos de mercado con fuerte enfoque regional que tal vez se perciban como no rentables e 
incapaces de recaudar dinero de fuentes tradicionales. Por lo tanto el crowdfunding no solo permite financiar proyectos importantes y lucrativos, al ayudar también a desarrollar otros menos potentes. La preventa es otro potencial que involucra a las empresas al recaudar pagos por adelantado sobre productos que se entregarán a posteriori (Hemer et al., 2011), financiando los costes fijos del producto antes de que comience la producción. Suele aplicarse para desarrollar un bien futuro que existe tan solo en forma de prototipo. Otro potencial permite incentivar la cocreación, beneficiándose de las aportaciones de la multitud, al retroalimentarse con las preguntas y sugerencias de mejora o innovadoras. El crowdfunding se basa en la idea de cocreación, en el sentido de que los patrocinadores están directamente integrados en la creación de valor (Blohm, Leimeister y Krcmar, 2013).

Del tradicional pasivo espectador de televisión y cine, se llega a la relación activa con el audiovisual que las nuevas tecnologías comportan. Surge la figura del prosumidor, que concentra en un único individuo roles que en el campo profesional asumen diversas personas. El vocablo fusiona producer y consumer en el anglicismo prosumer, uniendo los conceptos de productor y consumidor. Los usuarios devienen en prosumidores de su propio universo de imágenes, gracias a la interactividad que implementan los nuevos medios, permitiendo que cada individuo cree o envíe imágenes, aparte de simplemente recibirlas (Toffler, 1980). Integran las tres fases de gestión del contenido (producción, distribución, exhibición), permitiendo el crowdfunding aumentar aún más su perfil activo, al añadir la financiación. Como en todo proceso comunicativo, en el audiovisual participan el emisor y el receptor, junto al canal por el que circulan los contenidos. Esto tiene su equivalencia económica en la producción, distribución y exhibición. La desintermediación es uno de los grandes desafíos que plantea la migración hacia la tecnología digital, por el debilitamiento de los intermediarios tradicionales, el surgimiento de nuevos y el aumento de la relación directa entre productores y consumidores, forzándose un proceso de reintermediación (Rioux y Verdugo Ulloa, 2017). La digitalización transformó la tradicional cadena de valor, acercando a los creadores de películas a sus potenciales espectadores, sin ensambladores y con nuevos hábitos de consumo (Álvarez Monzoncillo, 2004). Independientemente del modo de distribución, del soporte de grabación o de la forma de exhibición, la lógica digital incita a participar en el proceso de financiación participativa (Clares, Ripoll y Tognazzi, 2013) pero también a sentirse importante en el nuevo rol de prosumidor, uniendo consumo y producción, cocreando y liderando las corrientes de opinión que fluyen por sus círculos sociales (Lamelo, 2016). Se pone en valor la cultura participativa con usuarios que interaccionan según un nuevo conjunto de reglas, pero no como un grupo uniforme, ya que cada usuario dispone de capacidades distintas para su participación activa (Jenkins, 2008), incluso protagonizando el fenómeno fan, apropiándose de lo mediático mediante una relectura que sirve a múltiples intereses, en pos de transformar la llamada cultura de masas en cultura popular (Jenkins, 2009). La idea de participación aplicada a la cultura, permite dirigirnos hacia un nuevo paradigma de política cultural, quizás en ciernes, cuyo punto fuerte "sería el protagonismo social en clave interactiva y colaborativa; es decir, el desplazamiento del Estado y del mercado por parte de la sociedad organizada como sujeto", pudiendo denominarse cultura compartida. Un paradigma sito "en torno a derechos culturales, de visibilidad de la diversidad, de dinámicas de interacción y cooperación y de gobernanza" (Zallo, 2017, p.87), que en el audiovisual sin duda camina hacia la oferta de contenidos producidos por no profesionales. El usuario inversor en crowd- 
funding comparte caracteres con el de la nueva televisión social. Usa su segunda pantalla para seguir activamente un programa por redes sociales y está informado de los proyectos en desarrollo gracias a Internet. El acto de ver televisión deja de ser lineal y pasivo para convertirse en proactivo, opinando o buscando información. El nuevo espectador es receptivo a las recomendaciones de personas de su universo social y consciente de que su opinión importa, operando simultáneamente como influenciadores e influenciados, creando sentimiento de comunidad (Neira, 2015). Además quieren decidir su nivel de compromiso con los creadores de contenido, formando parte e implicándose en lo que ven. Aunque no sean la mayoría, su crecimiento es sostenido y "determinante para generar dinámicas de comunidad alrededor de lo que producen las empresas de televisión" (Lamelo, 2016:48). Pero un consumo social 2.0 no evita el afán individual y personal, surgen nuevas vías de negocio diferenciando los contenidos, con accesos flexibles y ofertas personalizadas. "El usuario no solo se convierte en programador, sino que los canales interactivos le permiten también participar en la producción del contenido" (Diego, 2015:146). En el crowdfunding los usuarios interactúan con la web, pero también inciden en el origen del proyecto, pudiendo convertirse en coautores, no reconocidos, por sus aportaciones creativas y la proactividad incentivada en redes sociales por los promotores. Desde el modelo del crowdfunding puede ascenderse al estadio superior, el crowdsourcing, del que surge.

Internet altera el modelo analógico, facilitando la distribución autónoma e independiente de contenidos, permitiendo al espectador el anyone, anywhere y anytime. Los espectadores exigen ser libres de elegir y participar, quieren crear contenidos, pasando de la dictadura de los expertos a la sabiduría de la multitud (Álvarez Monzoncillo, 2011). El afán por intervenir en el proceso productivo se relaciona con la implicación emocional del espectador en su propio consumo cultural, ejemplificada en los contenidos compartidos (Roig Telo, 2010) que parecen infravalorarse porque pese a que "esa producción contribuye al bienestar colectivo de la sociedad, puede que no exista un número suficiente de espectadores, de forma individual, que estén dispuestos a sintonizar o pagar por ella" como para poder garantizarse la producción (Doyle, 2012:17). El audiovisual de proximidad aprovecha la proliferación de pantallas dirigiéndose al target de espectadores que reconocen los lugares en los que suceden los hechos que se cuentan, identificándose con sus protagonistas. Lo conocido deviene en materia esencial de trabajo del prosumidor audiovisual, primer espectador potencial. La inmersión del usuario en el rol productor se debe en parte a que busca crear los contenidos de los que también quisiera ser espectador. De alguna forma el crowdfunding plantea un intercambio económico que sustituye al pay per view o pago por visión de un producto, precomprando los derechos para poder contemplarlo una vez acabado, en una estrategia similar a la desempeñada por las cadenas de televisión en la financiación del largometraje cinematográfico. La precompra del derecho de emisión muta en la adquisición del derecho de visionado del producto cuando esté finalizado, con un soporte y ventajas acordes a lo invertido por cada mecenas. La relación de confianza entre las entidades (productora y cadena, promotor y mecenas) es semejante. El modelo de recompensa del crowdfunding halla su base en la pre-adquisición del derecho de visionado, aunque se complemente con otros alicientes que satisfacen el espíritu fan del mecenas mediante la contraprestación de productos propios del merchandising. Los inversores persiguen además otras recompensas morales, participando en el proceso de creación, mejora y difusión de productos, en especial cuando perciben que el modelo de negocio es justo 
para ellos (Franke y Klausberger, 2008). El crowdfunding fomenta la aparición de nuevos sectores de actividad donde es difícil obtener la financiación (Wojciechowski, 2009), con efectos positivos en la inclusión laboral, en especial entre grupos vulnerables, alentando a participar en el modelo de crowdfunding a personas con niveles distintos de inversión (Kleeman et al., 2008).

\section{Metodología de trabajo}

El objeto de estudio han sido los proyectos audiovisuales que han planteado su financiación mediante el lanzamiento de sus campañas a través de las plataformas de crowdfunding Verkami y Lánzanos, como dos de las principales existentes en la actualidad para cubrir las necesidades del sector a nivel estatal, por antigüedad, volumen y tasa de éxito. Ambas recogen un apartado específico para los productos audiovisuales, en el caso de Lánzanos bajo un único epígrafe denominado como "cine y animación", mientras que la plataforma Verkami subdivide el concepto "film" en los apartados de animación, cortometraje, documental, largometraje y webserie.

El propósito del trabajo se dirige al estudio de cómo este tipo de estrategias basadas en el modelo de crowdfunding pueden combinarse con la filosofía del crowdsourcing, con el fin de incentivar la producción en áreas geográficas no situadas en los dos grandes centros de producción audiovisual estatales, Madrid y Cataluña. Por este motivo, se ha realizado un trabajo previo consistente en el estudio de los datos sectoriales desde un perfil geográfico, tanto desde el punto de vista de la dispersión territorial de la producción como del consumo audiovisual, para afrontar la cuestión de los contenidos de proximidad. Posteriormente se han dividido los proyectos analizados de ambas plataformas en dos grandes grupos: productos documentales que tocan temáticas locales o de proximidad y largometrajes de ficción desarrollados por equipos no radicados en los grandes centros de producción a nivel estatal mencionados. Se ha procedido al estudio durante el mes de julio de 2016, de los dos grupos de proyectos con los caracteres mencionados, cuyo plazo de recepción de aportaciones había sido dado por finalizado en ese periodo en ambas plataformas, Verkami y Lánzanos. De las campañas que alcanzaron con éxito su objetivo se analizaron los ítems siguientes:

- Cifra económica establecida como objetivo y la realmente conseguida.

- Número de mecenas alcanzado y cantidades mínimas y máximas solicitadas.

- Fase del trabajo audiovisual (preproducción, rodaje o postproducción) en la que se ha creado la propuesta.

- Número de opciones de recompensas propuestas, descripción de la máxima recompensa y volumen de mecenas que han optado por la superior aportación.

- Grado de información sobre el destino concreto de los fondos solicitados. 
De igual manera han sido analizados los proyectos que no lograron alcanzar con éxito su objetivo de financiación, aplicando el estudio sobre los mismos ítems. Finalmente se ha procedido a la extracción de las conclusiones pertinentes.

\section{El sector audiovisual. El audiovisual extrarradial}

Independientemente de que el producto sea cinematográfico o televisivo, una empresa radicada en los grandes centros de producción, Madrid o Barcelona, contratará los servicios de los proveedores que le sean más económicos. El menor coste de transporte reducirá el precio final y tiempo de servicio de las empresas auxiliares cercanas. Los proveedores proporcionan las cámaras, iluminación, vestuario y decoración, transporte o catering necesarios para el rodaje, pero solo sobrevivirán allá dónde sus servicios se requieran regularmente. Si se ubican fuera del núcleo de actividad competirán con proveedores similares situados dentro de él, con menores costes y tiempos de transporte, por lo que estarán abocados al fracaso en un sector donde prima la inmediatez. Similar problema padecen los técnicos e intérpretes, ya que les contratarán productoras radicadas en los centros prioritarios de producción para ejercer su labor en dicho área, asumiendo los trabajadores los costes derivados. El audiovisual "extrarradial" pelea con que el sector profesional se centralice en dos comunidades, Madrid y Cataluña, aunque las televisiones autonómicas puedan alterar parcialmente la situación.

El riesgo es inherente al negocio cinematográfico. No hay certezas sobre el resultado económico de un film, dificultándose la supervivencia de las productoras al no depender "solamente del saber hacer sino también del azar, pues el éxito nunca esta garantizado" (Álvarez Monzoncillo, 2004:120). La excesiva atomización empresarial agudiza la debilidad financiera, forzando a diversificar las fuentes de financiación y a hipotecar el posible resultado comercial (Álvarez Monzoncillo y López Villanueva, 2007). Las estructuras empresariales en general son precarias o incluso inexistentes, basadas en modos de producción artesanal, fruto de proyectos unipersonales y ligadas al individuo-productor quien, pese a su saber audiovisual, suele carecer de la misma capacidad de gestión y estructura empresarial, incluso para reinvertir los excedentes cuando se producen (García Santamaría, 2016). La debilidad financiera y el reducido tamaño impiden simultanear producciones, obligando a apostar por un único proyecto cada vez, con incierto resultado comercial, ahondando en lo artesanal. Más del $75 \%$ de las productoras sufren el problema de participar en una sola película, que deberá tener éxito para poder afrontar la siguiente, repitiéndose el problema como muestra la evolución de las productoras que participaron en un solo film entre 2006 y 2016 (ICAA, 2016). 


\section{Tabla 1.}

\begin{tabular}{|l|c|c|c|c|c|c|c|c|c|c|c|c|c|}
\hline & 2006 & 2007 & 2008 & 2009 & 2010 & 2011 & 2012 & 2013 & 2014 & 2015 & 2016 \\
\hline & 183 & 213 & 217 & 234 & 249 & 259 & 246 & 267 & 276 & 343 & 354 \\
№ Productoras & 138 & 167 & 179 & 191 & 198 & 218 & 212 & 226 & 242 & 298 & 299 \\
Participación en una única película & 137 & 78,41 & 78,4 & 82,49 & 81,62 & 79,52 & 84,17 & 86,18 & 84,64 & 87,68 & 86,88 & 84,46 \\
Porcentaje sobre total & 75,41 &
\end{tabular}

FUENTE: Boletín Informativo 2016 ICAA.

Cabe preguntarse si la brecha existente entre las productoras consolidadas y las más artesanales, tiene una base únicamente financiera 0 el matiz geográfico agrava el problema de gestión. La televisión, configurada centralizando la emisión y recursos audiovisuales, permitió "un hiperdesarrollo del sector cultural industrial, una auténtica especialización productiva regional" en Madrid (Zallo, 2004, p.288). La formación de una relativamente importante industria de producción audiovisual está aquejada "de un fuerte proceso de concentración que amenaza la diversidad de su creación y la autonomía de su gestión", ya que la mayoría de las productoras fuertes son empresas con un alto grado de dependencia de las cadenas de televisión (Bustamante, 2004, p.230). La ubicación de las sedes televisivas en Madrid desplaza el poder de decisión a la capital, atrayendo a las productoras que las nutren de contenido. Las cadenas autonómicas podrían corregir parcialmente el problema. Atendiendo a lo cinematográfico, dónde puede presuponerse una menor dependencia de lo televisivo, se detecta un gran abismo geográfico que polariza el territorio estatal. En cuanto al volumen de películas participadas y al número de productoras allí radicadas (Tabla 2), las comunidades autónomas se dividen en tres grupos. Primero el formado por Cataluña y Madrid, que comanda la lista. Un segundo grupo compuesto por las comunidades con lengua propia (País Vasco, Valencia y Galicia), junto a Andalucía y Canarias. En este existe un nexo común, la televisión autonómica arraigada en sus territorios (compartido con Madrid y Cataluña). ETB, TV3 y TVG, nacidas respectivamente en 1982, 1983 y 1985, desarrollan su labor de fomento del sector desde entonces. La particularidad canaria se justifica en los mayores incentivos fiscales, con deducciones de hasta un $40 \%$ del coste de producciones rodadas en su territorio, superior al $20 \%$ medio estatal y en las facilidades de las subvenciones ministeriales a los proyectos de esta comunidad. En la cola están el resto, con un volumen de producción y registro de empresas cinematográficas absolutamente residual.

Retornando a la idea de riesgo, una forma de minorarlo para las productoras de cine es diversificar su actividad dirigiéndola también a la televisión. Cuando, por la concentración de las cadenas en Madrid, la opción se reduce para las empresas del resto del territorio, las televisiones autonómicas serán las únicas fuentes posibles tanto de diversificación del riesgo como de fortalecimiento económico apoyado en el resultado cierto del producto televisivo. El pluralismo, al menos geográfico, debería encontrar su modo de expresión y desarrollo mediante los nuevos modelos de negocio que permite 


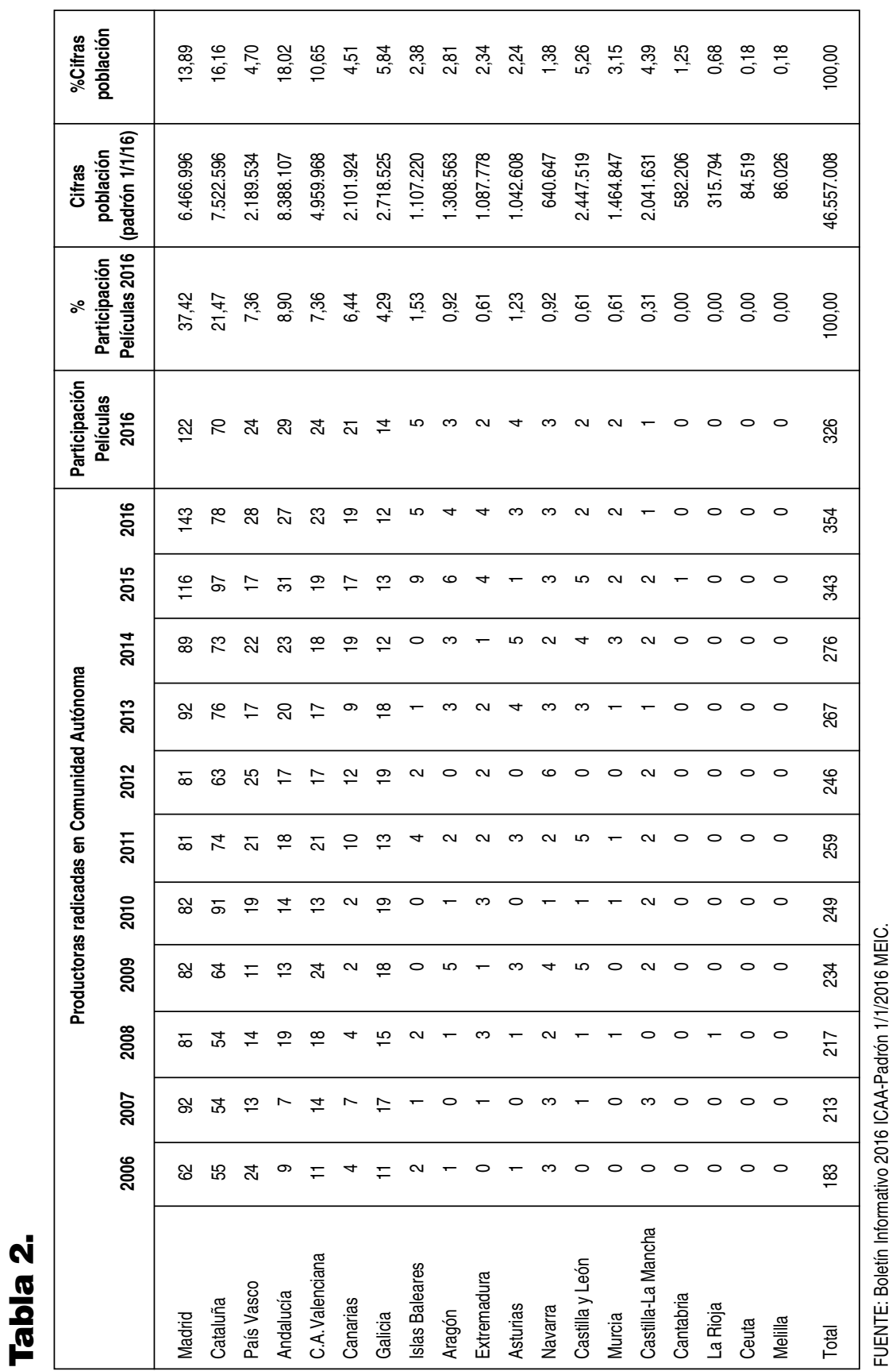


la red. Directa o indirectamente, las normas destinadas a gestionar la propiedad y concentración de los medios televisivos, persiguen el pluralismo y competencia en la producción y distribución de contenidos (Bustamante, 2017). La busca de un espacio audiovisual común para la Unión Europea ha chocado con el proteccionismo y el afán autárquico de los grandes estados. La lucha por protegerse del dominio norteamericano, ha alcanzado el no deseable resultado de reducir la diversidad cultural, impidiendo el acceso de productos de terceros países (Lange, 2001). Pero además ha logrado el perverso efecto de focalizar la identidad cultural en lo estatal, obviando las particularidades locales en las que no hay matices idiomáticos. La espacialización, que trata sobre el proceso para superar los límites geográficos mediante los medios de comunicación (Rodríguez Prieto y Martínez Cabezudo, 2016), también sería aplicable para romper las fronteras que el sector ha establecido centralizando su actividad en ciertas áreas, extendiéndose a otras zonas donde el tejido industrial está menos desarrollado. Uno de los ejes bipolares por el que se fabrica el camino de la transformación cultural en el mundo actual, se articula en la dupla globalización-identificación. La identificación cultural establece "Ia existencia de conjuntos de valores y creencias específicos en los que se reconocen determinados grupos humanos", como fruto, mayormente, de lo geográfico e histórico (Castells, 2010:165). La tecnología digital permite conjugar ambos extremos, la producción masiva destinada al mercado global y la distribución de contenidos personalizados. Si bien serán los grandes medios quienes operen en ambos frentes, en la actual era global los productores-usuarios tienen el tamaño mínimo necesario para personalizar sus contenidos y dirigirse a una parte localizable de los consumidores-usuarios (Castells, 2001). La diversidad y el pluralismo pueden alcanzarse rompiendo las fronteras internas del territorio, usando las nuevas tecnologías implementadas por Internet, las mismas que permiten saltar las barreras geográficas estatales para llegar a un mercado globalizado. Algunos desafíos del viaje migratorio digital, afectan en particular al mundo del crowdfunding, como la desmaterialización por la que el usuario actual liga el consumo al acceso al bien, sin necesitar de su posesión física. Internet se erige también en vector de reterritorialización y gestión de nuevos modos de gobernanza guiada por políticas estatales que "pueden tener un gran efecto estructurador en los elementos que determinan la diversidad de las expresiones culturales y, como consecuencia, en el desarrollo de las industrias culturales locales" (Rioux y Verdugo Ulloa, 2017:64).

\section{La financiación audiovisual}

Antes de afrontar la producción del contenido es preciso resolver el problema de la financiación. Un proyecto se gestiona a lo largo de tres fases consecutivas, preproducción, rodaje y postproducción final. El producto audiovisual es en esencia un prototipo individual que sigue un proceso de fabricación reconocido profesionalmente como know-how, con pasos obligados que parten del guion hasta llegar a la preproducción, como preparación previa al rodaje, en que se gestionan los equipos y mate- 
rial técnico necesario, búsqueda de localizaciones y casting. Una vez rodado en la grabación, el material se editará en la postproducción. El proceso sigue esquemas similares en proyectos diversos, independientemente de la pantalla de destino. Pese a ello, cada producto se confeccionará como un prototipo específico, distinto a los demás, no siendo factible un modelo de fabricación en cadena. El modo de trabajo se adapta a las peculiaridades estéticas y narrativas de cada proyecto, y a sus restricciones temporales (días de rodaje) y espaciales (localización). De igual forma la financiación se adaptará a las necesidades específicas de cada prototipo, sea televisivo o cinematográfico. El ámbito geográfico donde surja el proyecto afectará a la financiación, al ser distintas las ayudas públicas, existir o no una televisión autonómica, así como el riesgo percibido por las entidades financieras menos habituadas a la actividad audiovisual. Si el contenido es televisivo se establece con la cadena, como cliente directo, la fórmula de gestión para la productora. Existen dos modelos básicos, la producción financiada y la asociada, según asuma el coste total la cadena, percibiendo la productora su beneficio industrial o se busquen acuerdos parciales por los que se reparta el coste y derechos sobre el producto final. La financiación cinematográfica no cuenta con un cliente claro y definido, el volumen final de espectadores es una incógnita, por lo que el proceso se dificulta. En España la estructura de financiación de un largometraje destinado a exhibirse en salas de cine, se basa en tres ejes fundamentales. Las ayudas públicas, la preventa de sus derechos de emisión a una cadena de televisión, y por el último, los anticipos proporcionados por una empresa distribuidora (Cabezón y Gómez Urdá, 2004). El último no se ve afectado por la ubicación de la productora, más allá de la menor presencia en el área de decisiones del sector, pero en los dos primeros lo geográfico se adivina como una cuestión vital. Las ayudas públicas operan en distintos estratos. A nivel supranacional figuran las convocadas por organismos europeos, con los programas Creative Europe y Eurimages, mientras su traslación iberoamericana, Ibermedia, aplica un modelo similar al europeo. A nivel estatal, la política de fomento cinematográfico opera con subvenciones convocadas por el Ministerio de Educación, Cultura y Deporte, tendentes a incentivar sobre proyecto las producciones fílmicas. Finalmente las ayudas autonómicas, variables en cada territorio. Aunque administrativamente el acceso a ayudas internacionales y estatales no depende de la comunidad de origen, las autonómicas podrán solicitarse en función de la pertenencia del equipo a un territorio o del porcentaje del rodaje realizado en él. Estas ayudas buscan incentivar la actividad audiovisual en su área por lo que, en principio, afectan positivamente al sector local, y más si éste no pertenece a los grandes núcleos, Madrid y Cataluña.

En cuanto al segundo eje de la financiación, la preventa de los derechos de emisión del film en una televisión, encuentra su amparo en la Ley 7/2010, de 31 de marzo, General de la Comunicación Audiovisual, que en el artículo 5.3 establece que los prestadores del servicio de comunicación audiovisual televisiva, de cobertura tanto estatal como autonómica, están obligados a contribuir con el $5 \%$ de sus ingresos ( $6 \%$ si la titularidad es pública) participando en la financiación anticipada de producción europea. Se aplica a los canales que emitan contenidos financiables con una antigüedad de producción inferior a siete años. El artículo reconoce también el derecho a la diversidad cultural y lingüística, definiendo esta el grueso de la obligación (el $60 \%$ se empleará en contenidos en lenguas oficiales del estado). Las privadas destinarán el $60 \%$ a producción de largometrajes y las públicas el $75 \%$. La financiación consistirá en una participación directa en la producción o la compra de los dere- 
chos de explotación. Al aplicarse también a las cadenas autonómicas podría convertirse en un acicate para el desarrollo de la producción cinematográfica y televisiva local, más aún cuando se obliga a que al menos el $50 \%$ de la inversión se dirija a la obra de productores independientes. Este concepto se define en la Ley 55/2007, del Cine (art.4), como "aquella persona física o jurídica que no sea objeto de influencia dominante por parte de un prestador de servicio de comunicación/ difusión audiovisual". Las televisiones autonómicas externalizarán al menos la mitad de su inversión destinándola a empresas productoras no afines financieramente con ellas. Pero esto no siempre se cumple. La Comisión Nacional del Mercado de la Competencia (CNMC) analizó, en su informe de 4 de mayo de 2017, el cumplimiento de la obligación de financiación anticipada de las televisiones en el ejercicio 2015. Las Comunidades Autónomas elaboran los informes sobre sus televisiones, que son remitidos y estudiados por la CNMC. En 2015 se recibieron 12 informes del total de las comunidades obligadas a financiar obra europea (Andalucía, Aragón, Canarias, Castilla-La Mancha, Cataluña, Extremadura, Baleares, Galicia, Asturias, Madrid, Murcia y País Vasco). Otras cinco (Castilla y León, Cantabria, Valencia, La Rioja y Navarra) declararon no cumplir con los requisitos que obligan a financiar obra audiovisual europea (ni con ello estatal o local). Eludir la obligación programando contenidos producidos antes del periodo de los siete años previos implica, no solo que las televisiones no tengan que invertir en producción local adquiriendo derechos de explotación de metrajes que no están interesados en emitir (para no obligarse a invertir los siguientes años) sino que, previsiblemente, tampoco participarán en la producción de contenidos autolimitados a su vida comercial en salas, infringiendo un doble daño en la industria audiovisual autonómica. La CNMC recuerda la incompleta información dada por varias comunidades sobre sus ingresos. Con las entidades cumplidoras no existe conflicto, pero es previsible que los incumplimientos sean aún mayores al disminuir los ingresos declarados. Andalucía, Cataluña y Andalucía, respectivamente con 6.669.855 euros, 1.479 .398 euros y 447.138 euros superan ampliamente la inversión mínima a la que están obligadas por su volumen de ingresos. Incumplen, ordenadas de mayor a menor cuantía no invertida: Baleares, Aragón, Murcia, País Vasco y Madrid. Con balanza positiva de inversión, aunque con escaso margen, están el resto de televisiones evaluadas: Extremadura, Asturias, Castilla-La Mancha y Canarias (CNMC, 2017). Los datos confirman que la obligación de invertir en cine se dirige casi totalmente hacia producciones hechas en lenguas oficiales estatales, no al cine europeo. Pero el efecto real de la acción de las televisiones autonómicas en el desarrollo del tejido industrial territorial surge con el grado de cumplimiento de la inversión en obras creadas por productoras independientes. Cataluña, Galicia y País Vasco destacan por el elevado superávit en este aspecto, mientras que el resto generan datos negativos o muy reducidos. Así, solo las televisiones de comunidades con lengua propia apuestan por el desarrollo de la producción independiente, presumiblemente local. Este apoyo invita al crecimiento de su tejido industrial, permitiendo que las empresas detenten los derechos sobre sus contenidos. Lo no invertido en producciones independientes, iría por tanto a productoras dependientes de la operativa de cada cadena. Esto no impide que aumente su actividad mediante el encargo de proyectos, aunque implica que la propiedad del producto recae en las cadenas, no capitalizándose las empresas externas. Los datos del informe (CNMC, 2017) permiten deducir que únicamente las televisiones de comunidades con lengua propia cumplen su labor dinamizadora de la industria territorial cubriendo sus obligaciones. Las televisiones autonómicas públicas asumirán su papel incidiendo en tres aspectos básicos: la realidad cultural propia, la lengua y el patri- 
monio (cultural, social y territorial), pudiendo apoyarse en la producción local. El 75\% de las productoras que nutren de contenidos a las cadenas están radicadas en sus propios territorios, siendo la proximidad temática informativa un valor a desarrollar por estas televisiones. El 12\% de su programación se orienta a promocionar la industria y economía de su territorio, mientras el 19\% se destina a la emisión de contenidos culturales y sociales de su comunidad (Accenture, 2012). La asimétrica inversión en producción independiente se reafirma con los datos sobre su distribución territorial. Aunque el grado de cumplimiento de la televisión autonómica madrileña es negativo, en absoluto afecta al desarrollo del sector pues las sedes televisivas estatales llevan establecidas en dicha comunidad desde sus respectivos nacimientos.

También cabe cuestionarse si el consumo audiovisual varía en función de la comunidad. En cuanto al cinematográfico, el gasto medio por persona en 2016 fue de 13,1 euros (IVA incluido), con mínimos en Ceuta y Melilla (4,4 euros) y máximos en Madrid (20,4 euros) y Cataluña (15,9 euros) (SGAE, 2017), pudiendo deberse al mayor precio medio por entrada en las últimas (6,6 y 6,3 euros respectivamente frente a los 5,9 euros de media) y a la abundante oferta de salas (490 y 666 salas en Madrid y Cataluña) (ICAA,2016). El resto de autonomías alcanzan cifras homogéneas con una media de 11,6 euros. En cualquier caso se aprecia que aunque la cantidad gastada por espectador varíe geográficamente, son factores como el número de salas o el precio por entrada los que generan dispersión. En comunidades con un sector productivo débil es donde los espectadores apuestan con más vigor por películas estatales (Castilla y León (24,7\%), La Rioja (24\%), Aragón (23,8\%), Extremadura (23,5\%), Castilla-La Mancha (23\%) o Cantabria (22,7\%)) (SGAE, 2017). No son contenidos de proximidad, pero es allí donde la temática más cercana a la que pueden acceder, la española, interesa más. El paso de los años ha habituado al telespectador español a la cultura de pagar por ver televisión. La media de penetración en España de la televisión de pago ha sido del 9,6625\% entre 2008 y 2015. La cifra de distribución autonómica no muestra fuertes desvíos, salvo Extremadura, ligeramente por abajo (6,3625\%) y Asturias muy por encima de la media (17,525\%). Puede inferirse de ello que la disponibilidad para pagar por ver televisión, no difiere básicamente entre las comunidades (CNMC, 2018). El conjunto de televisiones autonómicas alcanzó un promedio de 7,6\% de cuota de pantalla en 2017, un leve aumento sobre el mínimo histórico del año anterior (7,4\%). Cabe valorar si la mínima cuota de pantalla se debe a una falta de interés en los contenidos de proximidad o al desapego al modelo de programación ofertado, homogeneizado con las estatales. La suma de audiencias de las distintas cadenas autonómicas logra sus máximos en áreas con lenguas propias: Cataluña (19\%), Galicia $(11,3 \%)$ y País Vasco (11\%). Andalucía (10,1\%) lidera las televisiones sin esta variable siguiéndola Aragón (8,3\%), Castilla-La Mancha (6\%), Extremadura (5,8\%), Asturias (5,7\%) y Canarias $(5,6 \%)$. Los territorios con menor audiencia son Baleares (2,7\%), Murcia (2,6\%) y Castilla y León (2,1\%). Situaciones particulares se dan en Madrid, con una audiencia de tan solo 5,4\% y la Comunidad valenciana con un $0,5 \%$. En el primer caso puede deberse al difuminado concepto de contenido de proximidad, al ser la capital foco de noticias estatales. En el segundo, el cierre de Canal Nou en 2013 recortó la oferta hasta casi anularla (Barlovento, 2018). 
La financiación parte de evaluar el coste de cada proyecto. El instrumento normalizado es el modelo oficial de presupuesto del Ministerio de Educación, Cultura y Deporte (MECD), dividiendo en partidas específicas las necesidades que requiere la producción de un contenido mediante 12 capítulos que recogen aspectos creativos, logísticos y financieros, que son potencialmente necesarios cubrir. El presupuesto medio de un largometraje español (ficción-documental) fue de 1,6 millones de euros en 2016, la mitad de la cifra empleada en 2010 (FAPAE, 2016). Un análisis sobre la distribución de los costes efectuado sobre una muestra de 44 largos con presupuesto superior a 900.000 euros (ICAA, 2016), acredita que el grueso se destina al pago del equipo humano, técnico $(24,17 \%$ ) y artístico (actores y actrices) $(11,01 \%)$, junto a guion $(2,09 \%)$ y música $(1,58 \%)$. Otros capítulos aluden al trabajo de empresas auxiliares cubriendo cuestiones como escenografía (7,6\%), estudios y varios $(6,25 \%)$, maquinaria y transportes (6,94\%) y procesos de laboratorio (4,27\%). El 6,18\% del total se destina a cubrir los intereses, porcentaje reducible gracias al crowdfunding al conseguir parte de la financiación mediante fondos sin el coste adicional de los intereses a reintegrar.

\section{Plataformas de crowdfunding: el caso de Verkami y Lánzanos}

De entre las plataformas estatales de crowdfunding basadas en recompensas destacan dos, Lánzanos, por ser la primera que operó en España ya en 2010, y Verkami, por su importancia y volumen. Ambas incentivan el desarrollo de proyectos culturales, y entre ellos atienden a la financiación de productos audiovisuales. Las páginas que ofertan sus servicios y los de sus promotores son www.verkami.com y www.lanzanos.com. Ambas funcionan según el modelo "Todo o Nada" por el que si no se alcanzan los objetivos de financiación mínimos, el proyecto se entiende como no conseguido ("sin éxito"), no formalizando los mecenas su participación económica (no se produce el pago). Verkami se especializa en proyectos culturales o artísticos, mientras Lánzanos cubre un campo generalista, incluyendo proyectos con objetivos solidarios. Las comisiones con las que operan, y de las que obtienen su rendimiento económico, son del $5 \%$ en ambos casos, aunque Lánzanos minora el porcentaje al $1 \%$ cuando se trata de proyectos solidarios. Verkami establece un plazo de 40 días para alcanzar la cantidad objetivo del promotor, mientras que Lánzanos no marca un plazo concreto aunque limita a 90 los días en que la campaña puede permanecer online. Define también una fase inicial llamada "La Caja", previa a la aceptación del proyecto, para valorar su inclusión exponiéndola a la opinión de la comunidad de usuarios. Superan la fase (que no es obligada) los proyectos que consigan más de 100 votos. En sus páginas se identifican como plataformas de crowdfunding o micromecenazgo explicando didácticamente el proceso a los posibles promotores y mecenas y recordando que el objetivo de las inversiones no es obtener beneficios económicos, sino la recepción de recompensas en forma de productos, servicios o experiencias a cambio de la aportación. Enuncian que el autor del proyecto mantiene la totalidad de los derechos, siendo además responsable del cumplimiento de las recompensas ofrecidas. Verkami insiste en la cuestión legal al calificar jurídicamente al crowdfunding como 
un anticipo a cuenta de una compra o adquisición futura de un bien o servicio, evitando la confusión con el concepto de donación al existir una contraprestación. Definen también que se tratan de compromisos de aportación y no aportaciones directas, ya que de no lograr la meta de financiación no se formalizará el pago. Ambas webs desglosan el importe de su comisión (5\%) así como las formas de pago, con tarjeta y vía PayPal en Verkami, y también mediante transferencia bancaria o con un sistema de vales offline para aquellos mecenas que no deseen utilizar sus datos bancarios en el caso de Lánzanos, que ofrece un servicio llamado Lánzanos Pro, poniendo a disposición de entidades públicas o privadas sus propias plataformas de crowdfunding para agrupar proyectos afines a las instituciones. Ambas entidades se comprometen a dar una respuesta rápida a los aspirantes a promotores sobre la viabilidad o no de su campaña, antes de 72 horas en el caso de Lánzanos y entre 3 y 5 días laborables en el de Verkami. Un estudio sobre plataformas de crowdfunding españolas en los años 2012 y 2013, destaca que la mayoría de sus éxitos pertenecen al campo de la cultura, entretenimiento y proyectos sociales, contando con un potencial laboral muy alto. Cada proyecto del sector cultural generó tres empleos de media durante 2012, aunque sus campañas a menudo se relacionan con el autoempleo. Las tasas de éxito de Verkami (81.39\%) y Lánzanos (61.08\%) fueron de las más altas. La crisis económica conlleva una gran dificultad de acceso a los tradicionales canales de financiación, por lo que son particularmente interesantes alternativas como el crowdfunding como instrumento promotor de la actividad económica y laboral, en países con alta tasa de desempleo como España (Ramos y González, 2016).

\section{Desarrollo y resultados}

Ambas plataformas disponen sus páginas en un esquema de interfaz similar, distribuido en dos columnas. A la izquierda se ubica la descripción de la campaña, mientras que en la derecha se enumeran y describen las recompensas que se ofrecen a cambio de las aportaciones. Verkami añade el blog del proyecto y una descripción del autor. La reseña sobre el emprendedor se sitúa al final de la columna izquierda de la página de Lánzanos. Ambas webs proponen al promotor el uso de un video explicativo (alojado en Youtube o Vimeo) y facilitan la utilización de imágenes que permitan visualizar las particularidades del proyecto. Se insertan enlaces a redes sociales para compartir la campaña. La retroalimentación en red es un punto fuerte, estableciendo comunicaciones constantes entre promotores y mecenas, que no solo resuelve dudas sobre proyectos o recompensas, pues habitualmente se ofrecen soluciones o proponen temas o personajes de interés para el metraje. No solo existe interés en que el proyecto salga adelante, sino también el deseo de participar en el contenido asumiendo el rol prosumidor. 


\begin{tabular}{|c|c|c|c|c|c|c|c|c|c|c|}
\hline 胥 & 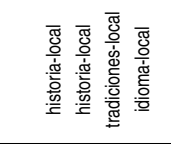 & 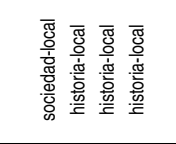 & 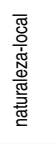 & 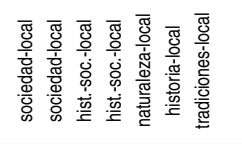 & 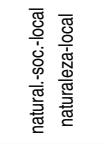 & 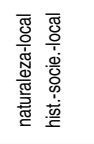 & 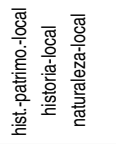 & 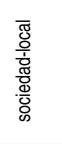 & 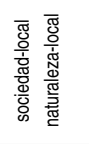 & 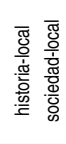 \\
\hline 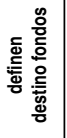 & $\bar{\omega} \bar{\omega} \bar{\omega}$ & क कं कं क & $\bar{\omega}$ & 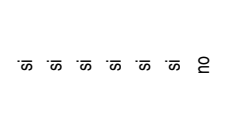 & $\bar{\omega} \bar{\omega}$ & $\bar{\omega} \bar{\omega}$ & $\bar{\omega} \bar{\omega} \bar{\omega}$ & $\bar{\omega}$ & 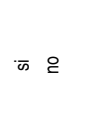 & क के \\
\hline 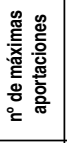 & no - m & $\stackrel{\infty}{\frac{\pi}{0}} \circ \frac{\frac{\pi}{0}}{\frac{0}{2}}-$ & $\circ$ & 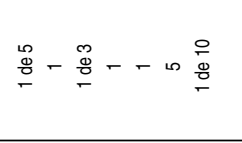 & $-\frac{\circ}{8}$ & $+\infty$ & 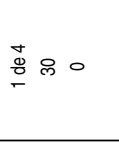 & m & 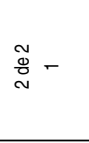 & -+ \\
\hline 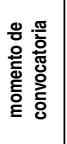 & 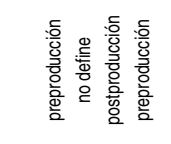 & 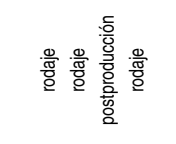 & $\frac{.0}{\sqrt[3]{0}}$ & 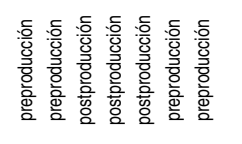 & 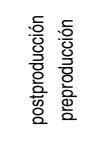 & 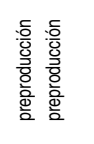 & 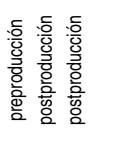 & 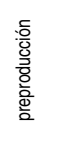 & 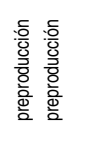 & 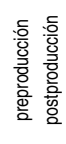 \\
\hline 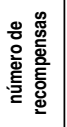 & $m \infty 0 m$ & $\mp \stackrel{9}{\simeq} \simeq$ & 우 & $=0=\stackrel{\circ}{=} \circ \wedge 0$ & $\infty \stackrel{m}{=}$ & $\simeq$ 우 & 우 $\forall \pm$ & $\wedge$ & $\infty \infty$ & $\simeq 0$ \\
\hline 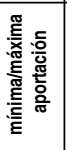 & 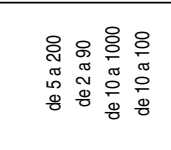 & 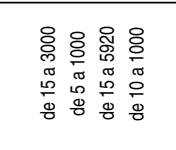 & $\begin{array}{l}8 \\
\frac{8}{0} \\
\frac{0}{0} \\
\frac{0}{0} \\
0\end{array}$ & 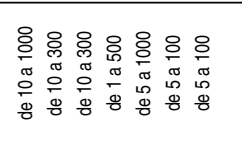 & $\begin{array}{ll}0 & 8 \\
0 & 0 \\
0 & 0 \\
0 & 0 \\
0 & 0 \\
0 & 0 \\
0 & 0\end{array}$ & 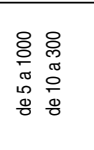 & $\begin{array}{lll}8 & 0 \\
0 & 0 & 0 \\
0 & 0 & 0 \\
\sigma & 0 \\
0 & 0 \\
0 & 0 \\
0 & 0 \\
0 & 0 & 0 \\
0 & 0\end{array}$ & $\begin{array}{l}\stackrel{8}{0} \\
\stackrel{0}{0} \\
\stackrel{0}{0} \\
0\end{array}$ & $\begin{array}{ll}8 & 0 \\
0 & 0 \\
0 & 0 \\
0 & \pi \\
0 & 0 \\
0 & 0 \\
0 & 0\end{array}$ & $\begin{array}{ll}8 & 8 \\
0 & 0 \\
0 & 0 \\
0 & 0 \\
0 & 0 \\
0 & 0\end{array}$ \\
\hline 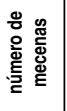 & প్ల & 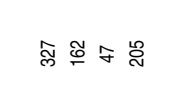 & $\stackrel{\infty}{\sim}$ & 下 & 虽邑 & 옹 & $\stackrel{\infty}{=}$ 的嵒 & 志 & \& $\stackrel{\infty}{\sim}$ & 邑 \\
\hline 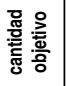 & 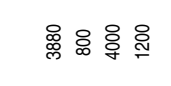 & 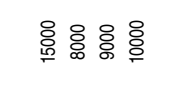 & : & 守遌 & ০ : & 옹 总 & 各 옹 웅 & 吕 & 용 용 & 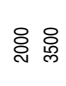 \\
\hline 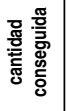 & 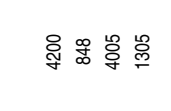 & 옹융 융 웡 & 옹 & 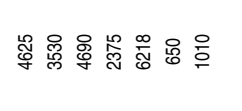 & ్్ㅇ용 & 号㤐 & 怘 怘 & 兽 & 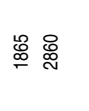 & 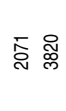 \\
\hline 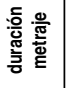 & 용ㅎㅇ & 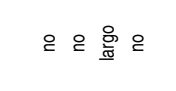 & ○ & 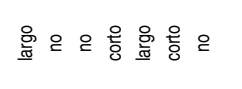 & 옹 & 응 웅 & $\therefore \circ \underset{\frac{8}{9}}{\stackrel{8}{\pi}}$ & & $\stackrel{\circ}{\simeq}$ & ㅇ \\
\hline 苑 & 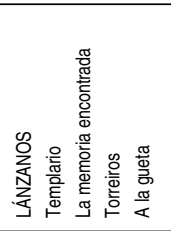 & 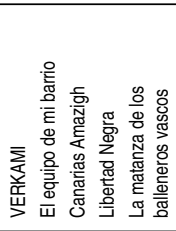 & 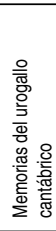 & 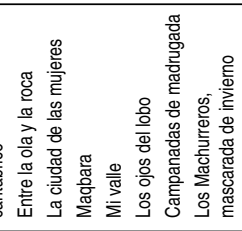 & 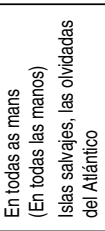 & 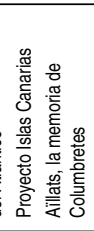 & 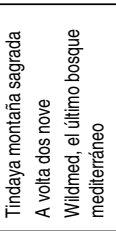 & 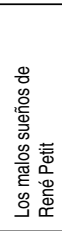 & 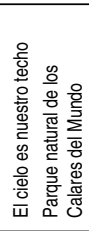 & 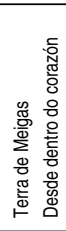 \\
\hline
\end{tabular}


La tabla 3 recoge las cuestiones estudiadas en los proyectos documentales con temática local. Los datos se han extraído de cada una de las campañas planteadas por los promotores, en sus respectivos apartados dentro de las páginas web de ambas plataformas. El volumen de información es abundante, así como la transparencia de los datos proporcionados, aunque es reseñable que en la plataforma Lánzanos se evitan referencias a los proyectos fallidos. Las descripciones de los proyectos no siguen una estructura predefinida aunque tocan aspectos similares, siendo los más habituales el tema y justificación del proyecto; los objetivos sociales a alcanzar; la información sobre autores, equipo, necesidades a cubrir, calendario y plazos de trabajo; colaboraciones de instituciones y notas de prensa; aclaraciones sobre las recompensas o modos de pago y la trayectoria previa de la entidad promotora. Es reseñable que, siguiendo las recomendaciones de ambas plataformas, se incide fundamentalmente en lo emocional. La descripción de los proyectos se basa en destacar las peculiaridades e interés humano y/o social, de los personajes protagonistas, del espacio natural o monumental 0 del periodo histórico tratado. Esta descripción debería basarse en los puntos fuertes definidos por una campaña de comunicación coherente, con una correcta elección del público objetivo y del canal para llegar a él, aprovechando los caracteres de los canales y los potenciales mecenas, para definir la descripción y difusión adecuadas (Coronado Ruiz y Larrañaga Rubio, 2015). Si bien, en la mayoría de los casos, se desglosa a que va destinarse la cifra financiada, la temática es el eje descriptivo del proyecto pero, frente a lo que incluiría un dossier de producción destinado a una entidad financiera, no se describe audiovisualmente el proyecto, en muchos casos ni siquiera se define si se trata de un largo 0 un cortometraje documental. No se incluyen cuestiones como sinopsis, listado de localizaciones, narrador del metraje, plan de rodaje o presupuesto del proyecto. Con ello en pocas propuestas se muestra lo que sería profesionalmente obligado en un dossier. Sin embargo (no siempre con claridad), se presenta el dato de la fase en que está el proyecto, sea preproducción, grabación o postproducción. La primera columna de la tabla refleja las situaciones en las que se ha definido o no la duración del contenido, dividiéndolos en largos y cortometrajes. La importancia del dato no es la de concretar un minutado exacto, sino que la forma de afrontar un proyecto es radicalmente distinta, tanto por el presupuesto necesario u opciones de distribución, como por definir la dificultad real para que un proyecto más complejo como un largometraje pueda realizarse. La mayoría de las veces no se explica con nitidez, siendo una información esencial y obligada para cualquier posible partícipe en un proyecto. Igualmente importante es conocer la fase en que se encuentra el producto al convocar la campaña, dato habitualmente proporcionado, aunque no con la claridad deseable. La preproducción es clave en términos de engagement social, al decidirse los aspectos básicos de su identidad (Neira, 2015), aspecto que incitaría a una mayor participación por parte de los aportantes más activos. Sin embargo una mayor cercanía al momento final del producto implica un menor riesgo en la inversión, por lo que debería ser un punto positivo a añadir. También convendría conocer el coste global estimado del proyecto y con ello, el porcentaje sobre el total que queda por cubrir, que apenas es descrito, como tampoco el plan de financiación global. Como prototipo, el producto ha de hacerse con el dinero necesario, nunca con menos, ya que la menor dotación económica se reflejará en la calidad formal del metraje final. Por ello el objetivo de financiación concreto de cada proyecto, no permite extraer conclusiones claras sobre el grado de utilidad del mismo para el desarrollo efectivo de cada 
propuesta. Más cantidad recaudada no significa una mejor calidad del producto si no se dispone del ratio que supone sobre el presupuesto total del proyecto.

El uso como herramienta de trabajo de la estructura capitular del Presupuesto Oficial, proporcionaría un modelo idóneo para cuantificar e identificar las partidas sobre las que se requiere financiación, así como para definir la fase real del trabajo en que se halla el proyecto. El capítulo 1 recoge costes propios de la preproducción (guion) y la postproducción (música). A esta fase corresponden los capítulos 9 y 12, mientras que el resto se aplican en general al rodaje, aunque dentro de cada uno, existen subgrupos de partidas que pueden situarse con certeza en una fase concreta. Por ejemplo viajes y costes de alojamiento, precisos en preproducción, se definen en el grupo 7.1 "Localizaciones" mientras que el 5.2 "Montaje y sonorización" se usa en postproducción. Así la utilización del modelo público de presupuesto, permitiría organizar el calendario de crowdfunding adaptándolo a las necesidades del presupuesto, estratificando la financiación en tramos distintos y consecutivos. Las recompensas deberían adecuarse para generar un colectivo de financiadores que cubriesen sus expectativas de participación. Estas recompensas muestran la buena voluntad del promotor, manteniendo un esquema que va desde la entrega de la copia final en DVD, en los casos de menor cuantía, hasta insertar los logos y nombre de las instituciones como patrocinadores, cuando se aporta el máximo. Se usa repetitivamente el término "productor" como premio, aunque esto implicaría una participación en los posibles beneficios del proyecto o incluso en los derechos sobre el mismo, cuestión que las plataformas explícitamente eliminan como recompensa posible. De nuevo es lo sentimental el elemento de llamada para las personas físicas, no para las instituciones o empresas. Se apela a que el mecenas se sienta una figura importante del proceso, con una mención personalizada como productor en los créditos. Se combina el valor emocional y la sensación de interacción directa con el promotor (Rubio, Rius y Martínez, 2014). En niveles bajos de inversión, el merchandising cubre el fetichismo del usuario, siempre que denote un matiz de autoría y de aprecio en los detalles que se ofrecen (Clares et al., 2013).

Las aportaciones mínimas y máximas propuestas a cambio de recompensas, siguen criterios sugeridos por las plataformas al diversificar las opciones. Esto es relevante ya que en muchas ocasiones no se cubren las expectativas máximas de contribución. Por ello, el número final de mecenas de cada proyecto tiene múltiples picos, partiendo del mínimo de 12 a un máximo de 327 . En el primer caso la cuantía total aportada es de 650 euros y la media de 54,16, en el segundo se logra 16.190 euros, mientras que la media por cada mecenas es de 49,51 euros. Los temas tratados van desde aspectos concretos de la historia local, parajes naturales y patrimoniales de la zona, hasta asuntos de interés social para la comunidad, existiendo un tamaño temático uniforme. Lo universal puede reflejarse en lo cercano, que es el eje de trabajo. El colectivo-usuario conocedor previo del escenario local y de la pequeña historia que toda comunidad acumula en su memoria, es el potencial primer espectador de los productos y, previsiblemente, mecenas adecuado para los mismos, independientemente de que pueda alcanzar una repercusión posterior mayor geográficamente hablando. La tabla 4 refleja las campañas para proyectos de largometraje iniciadas y completadas, que tienen como base de operaciones áreas geográficas ajenas a los centros de producción prioritarios estatales. La tabla 5 muestra los intentos fallidos. Los ítems empleados son similares a los usados en proyectos documentales. Existe un nexo 


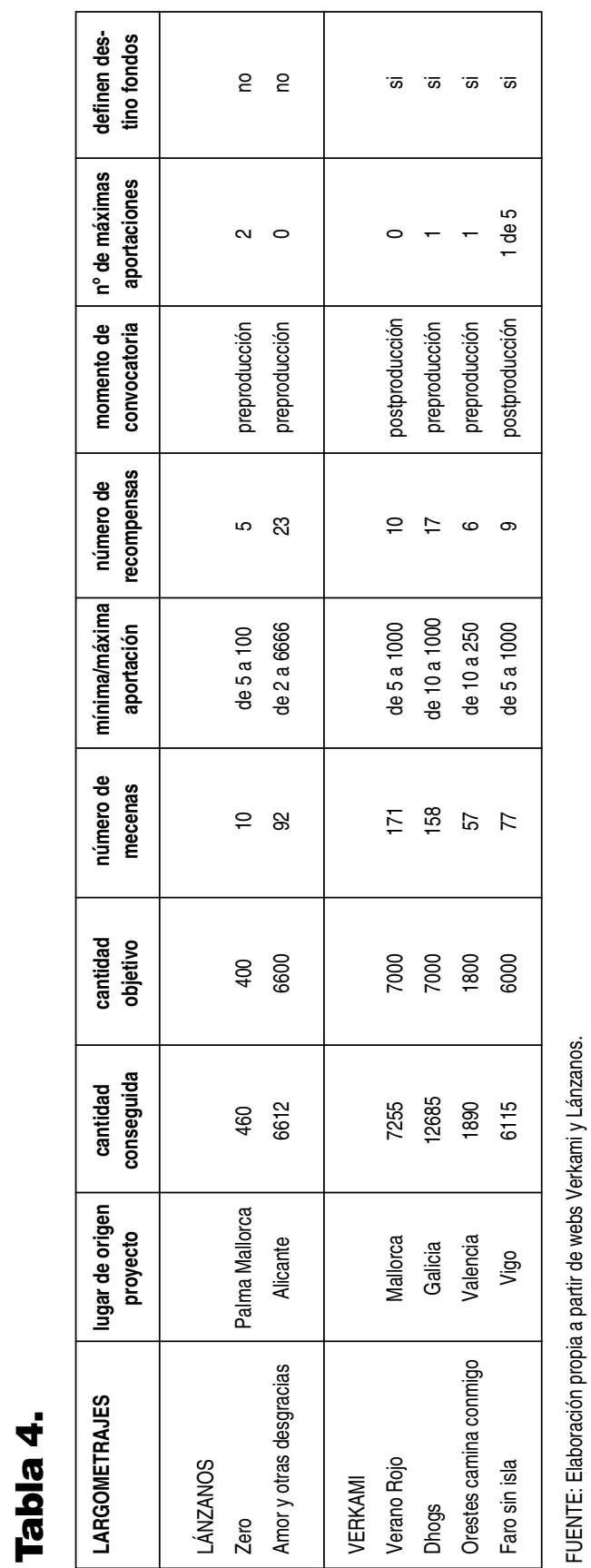




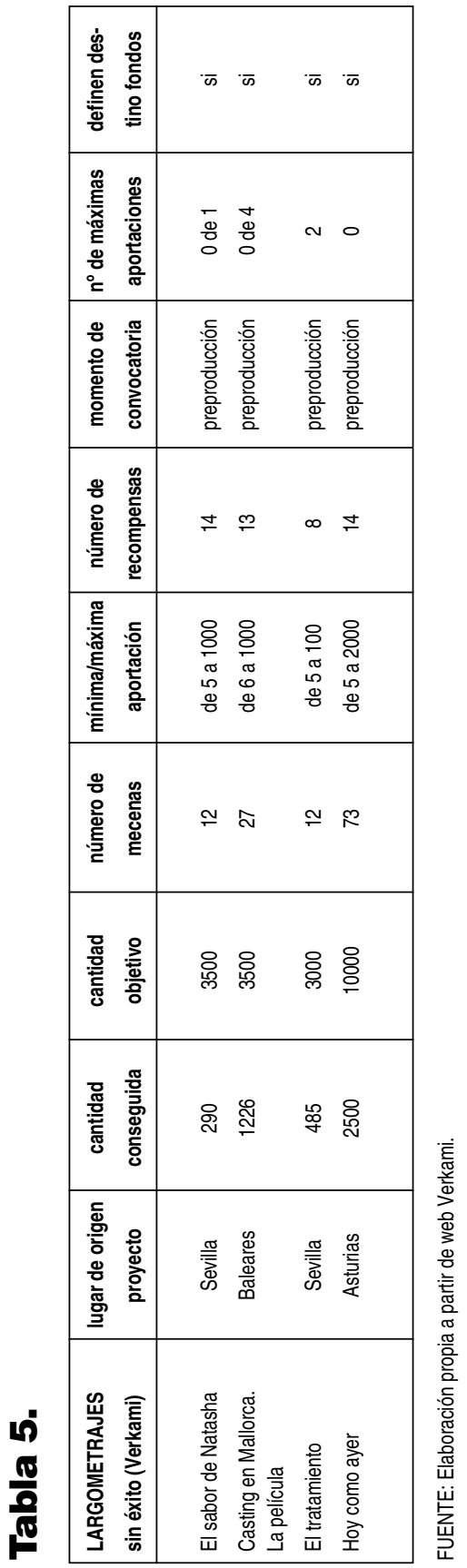


común, el escaso volumen presupuestario pretendido y alcanzado. Un largometraje profesional precisa de una cantidad variable pero importante de dinero para acometerlo. Los proyectos estudiados no alcanzan las cantidades mínimas habituales estimadas para largos, estando muy alejadas de la media presupuestaria del sector, pudiendo inferirse que su forma de actuar está más cercana al amateurismo que al mundo profesional, aunque no proporcionan los datos suficientes para afirmarlo. En este caso, lo destacable son las posibilidades que tendría una combinación de una estrategia de crowdfunding con otra de crowdsourcing para incentivar la actividad profesional audiovisual de estas geografías. Las aportaciones de una parte de los mecenas pueden dirigirse, a cubrir la financiación a cambio de recompensas, pero tendría mucho sentido ofrecer la opción de aportación, colaborando mediante la experiencia profesional acumulada de muchos usuarios, capacitados por sus conocimientos para desarrollar las labores propias de cada departamento. El audiovisual es un trabajo en equipo ejercido por especialistas en la dirección, producción, dirección artística, fotografía, vestuario, maquillaje y peluquería, sonido o edición. Iniciativas ejercidas en este sentido por los promotores de los proyectos pueden posibilitar la inserción en su grupo de trabajo de estos usuarios- prosumidores, aportando su buen hacer. Muchos de los proyectos de largometraje pecan de un amateurismo que precisa de otro tipo de asesoramiento 0 ayuda que va más allá de una mera aportación económica puntual. Se observa que la tasa de fallo es relativamente alta en estas campañas, quizá por no asumir la medida económica que implica la producción de un largo, por humilde que sea. Las recompensas deberían encuadrarse en la legalidad y propósitos de este tipo de plataformas pero, aún con ello, se observa un nicho de actuación esencial para facilitar el impulso del volumen de actividad profesional, más constante y estable, que pueda permitir el nacimiento de un tejido industrial en este sector, inexistente en muchas áreas geográficas. Frente a otras parcelas de la economía colaborativa en que la plataforma es el centro de organización y gestión del negocio, como nexo necesario de unión entre los interesados (Alfonso, 2016), en el audiovisual la plataforma ofrece una vía de financiación adicional, pero no obligada, pudiendo sin embargo convertirse en motor y dinamizador del sector a nivel local.

\section{Conclusiones}

La persistente evolución tecnológica del sector audiovisual se acompaña de una constante readaptación de su modelo de negocio, aprovechando las prácticas colaborativas que facilita Internet y el uso de las redes sociales, incluyendo la fase de financiación de los proyectos. En este sentido el crowdfunding permite a los usuarios la extensión del rol prosumidor, incentivándoles a participar en la fase germinal del proyecto mediante la aportación de fondos y sugerencias que les conviertan en parte activa del producto, satisfaciendo sus inquietudes al hacerles sentirse coautores del mismo. Así, plataformas de crowdfunding como Verkami o Lánzanos, permiten a los mecenas convertirse en agen- 
tes motores de los proyectos audiovisuales que les resulten más afines por la temática tratada o por su cercanía física o ideológica, pero también en sus primeros espectadores potenciales. Este modelo puede asimilarse a una combinación del denominado pay per view (por el que se paga por ver un contenido concreto) con la precompra de los derechos de emisión de un producto cinematográfico por parte de una cadena televisiva, una de las bases fundamentales del modelo de financiación del cine. La asimetría empresarial del sector productivo estatal, concentrado en Madrid y Cataluña, discute el desarrollo de un audiovisual plural en España, ampliando la brecha cultural y laboral del sector, y dificultando la creación de un tejido industrial más allá de estas comunidades, incluso para el acceso a una posible financiación. En este sentido, el crowdfunding permite aprovechar la ruptura de los límites físicos que faculta Internet para poner en valor la idea de proximidad como instrumento de venta del proyecto, a la par que en elemento definidor del público objetivo, siendo dicha proximidad un medio para convertir las plataformas en un sistema de comunicación que ponga en relación a los productores locales con usuarios que pueden aportar su experiencia y conocimiento para un mejor desarrollo de cada proyecto, en un modelo asimilable a la filosofía del crowdsourcing. Esto debería facilitar un trabajo continuado en el tiempo, en pos de la generación de contenidos audiovisuales distintos y consecutivos, con el objetivo final de sentar las bases de un tejido industrial audiovisual en áreas geográficas en las que no exista o sea débil.

Los datos extraídos del análisis de las campañas propuestas en las plataformas Verkami y Lánzanos, permiten concluir que los proyectos pecan de cierto amateurismo que les impiden aprovechar completamente las posibilidades que el modelo de crowdfunding oferta. Entre los problemas detectados destacan la falta de información concreta sobre el presupuesto total, la fase en que se encuentra el proyecto, el destino de los fondos e incluso la definición del producto como largo o cortometraje. También se percibe una excesiva confianza en la predisposición de los potenciales inversores y una falta de delimitación del público objetivo que permitiese el desarrollo de campañas mejor estructuradas. Por ello, sobre todo en el caso de los largometrajes, se infiere un sobredimensionamiento de la capacidad real del promotor para llevar a cabo su producto y una percepción idealista sobre las necesidades económicas del mismo. Así las cifras obtenidas pueden entenderse como residuales y tendentes a resolver el problema puntual de lograr finalizar el film. El Presupuesto Oficial puede usarse como instrumento planificador de la financiación basada en el crowdfunding, mediante la segmentación de las fases de confección del producto audiovisual, preproducción, rodaje y postproducción, con su traslación al desarrollo de campañas organizadas según dichos periodos y las partidas presupuestarias a las que se destinan los fondos. Esto permitiría una gestión coherente de la financiación y dotar de información objetiva a los mecenas, involucrándoles más a lo largo del tiempo en el proyecto, incluso laboralmente. Sería obligado, en cualquier caso, asumir la medida real de los proyectos para, aprovechando los potenciales hedonista y altruista del crowdfunding, permitir su uso en la creación de un tejido audiovisual local, mediante el efecto llamada sobre la idea de bien común del territorio, junto a una gestión profesionalizada del proceso. 


\section{Bibliografía}

ACCENTURE (2012): Informe sobre el papel de la Televisión Pública Autonómica en España. Recuperado de http://www.forta.es/Portals/0/Forta1200.pdf

AGRAWAL, A., CATALINI, C. \& GOLDFARB, A. (2011): Offline relationships, distance, and the Internet: The geography of crowdfunding. Recuperado de: http://pages.stern.nyu.edu/ atakos/ResearchCamp/ agoldfarbpaper.pdf.

ALFONSO, R. (2016): "Economía colaborativa: un nuevo mercado para la economía social", CIRIECEspaña, Revista de Economía Pública, Social y Cooperativa, 88, 231-258, DOI: 10.7203/CIRIECE.88.9255.

ÁLVAREZ MONZONCILLO, J.M. (2004): "La industria cinematográfica: enfermedades crónicas e incertidumbres ante el mercado digital". En: Bustamante, E. (Coord.), Comunicación y cultura en la era digital, Barcelona: Gedisa, 107-140.

ÁLVAREZ MONZONCILLO, J.M. \& LÓPEZ VILLANUEVA, J. (2007): La situación de la industria cinematográfica española: políticas públicas ante los mercados digitales, Madrid: Fundación Alternativas.

ÁLVAREZ MONZONCILLO, J.M. (Coord.) (2011): La televisión etiquetada: nuevas audiencias, nuevos negocios. Barcelona: Ariel y Fundación Telefónica.

BELLEFLAMME, P., LAMBERT, T. \& SCHWIENBACHER, A. (2010): "Crowdfunding: An Industrial Organization Perspective". En Prepared for the workshop Digital Business Models: Understanding Strategies, held in Paris on June 2010, 25-26.

BELLEFLAMME, P., LAMBERT, T. \& SCHWIENBACHER, A. (2014): "Crowdfunding: Tapping the right crowd", Journal of Business Venturing, 29(5), 585-609, DOl:10.1016/j.jbusvent.2013.07.003.

BARLOVENTO (2018): Análisis Televisivo Año 2017. Recuperado de https://www.barloventocomunicacion.es/blog/178-analisis-televisivo-2017.html.

BLOHM, I., LEIMEISTER, J.M. \& KRCMAR, H. (2013): "Crowdsourcing: How to benefit from (too) many great ideas", MIS Quarterly Executive, 12(4), 199-211.

BRABHAM, D.C. (2008): "Crowdsourcing as a Model for Problem Solving: An Introduction and Cases", Convergence: The International Journal of Research into New Media Technologies, 14(1), 75-90, DOI: $10.1177 / 1354856507084420$.

BRÜNTJE, D. \& GAJDA, O. (eds.) (2016): Crowdfunding in Europe. State of the Art in Theory and Practice, Springer. DOI: 10.1007/978-3-319-18017-5. 
BUSTAMANTE, E. (2004): "Televisión: errores y frenos en el camino digital". En: Bustamante, E. (Coord.), Comunicación y cultura en la era digital, Barcelona: Gedisa, 213-264.

BUSTAMANTE, E. (2017): "Indicadores y diversidad en la industria audiovisual: la lucha por la diversidad apenas ha comenzado". En: Albornoz, L.A. \& García Leiva, M.T. (Eds.), El audiovisual en la era digital, Madrid: Cátedra, 137-160.

CABEZÓN, L.A. \& GÓMEZ URDÁ, F.G. (2004): La producción cinematográfica, Madrid: Cátedra.

CASTELLS, M. (2001): La galaxia Internet, Madrid: Areté.

CASTELLS, M. (2010): Comunicación y poder, Madrid: Alianza.

CLARES, J., RIPOLL, J. \& TOGNAZZI, A. (2013): Distribución audiovisual en Internet. VOD y nuevos modelos de negocio, Barcelona: Editorial UOC.

CNMC (Comisión Nacional del Mercado de la Competencia) (2017): Informe sobre el cumplimiento en el ejercicio 2015, financiación obra europea. Recuperado de https://www.cnmc.es/sites/default/files/1629848_3.pdf.

CNMC (Comisión Nacional del Mercado de la Competencia) (2018): CNMCDATA. Datos estadísticos. Recuperado de http://data.cnmc.es/datagraph/.

CORONADO RUIZ, C. \& LARRAÑAGA RUBIO, J. (2015): "La financiación por medio del crowdfunding del audiovisual: el caso del cortometraje Juan y la nube", Documentación de las Ciencias de la Información, 38, 203-221. DOl:10.5209/rev_DCIN.2015.v38.50816.

CORRECHER MATO, C.J. (2017): "Consumo colaborativo y entidades sin fines lucrativos: aspectos fiscales", CIRIEC-España, Revista Jurídica de Economía Social y Cooperativa, 31, 253-277.

DE VOLDERE, I. \& ZEQO, K. (2017): Crowdfunding. Reshaping the crowd's engagement in culture, Luxembourg: Publications Office of the European Union. DOI: 10.2766/011282.

DIEGO, P. (2015): "Estrategia multiplataforma de la Televisión conectada". En Medina, M. (Coord.), La audiencia en la era digital, Madrid: Fragua, 145-169.

DOYLE, G. (2012): "Economía audiovisual: los mercados audiovisuales", Quaderns del CAC, 38, vol. XV (1), junio, 15-24.

FAPAE (Federación de Asociaciones de Productores Audiovisuales Españoles) (2016): Datos provisionales cine en España 2016. Recuperado de http://www.fapae.es.

FIEDLER, S. \& HORSCH, A. (2014): "Crowdinvesting als Finanzierungsalternative", Zeitschrift für KMU und Entrepreneurship, 1, 91-98, DOI: 10.3790/zfke.62.1.91.

FRANKE, N. \& KLAUSBERGER, K. (2008): Design communities: Business model of the future? Recuperado de http://noori.abismo.org/crowdsourcing.pdf. 
GARCÍA SANTAMARÍA, J.V. (2016): Los grupos multimedia españoles. Análisis y estrategias, Barcelona: Editorial UOC.

HAAS, P., BLOHM, I. \& LEIMEISTER, J.M. (2014): "An empirical taxonomy of crowdfunding intermediaries". In: $35^{\text {th }}$ International Conference on Information Systems (ICIS), Auckland, New Zealand.

HEMER, J., SCHNEIDER, U., DORNBUSCH, F. \& FREY, S. (2011): Crowdfunding und andere Formen informeller Mikrofinanzierung in der Projekt- und Innovationsfinanzierung, Stuttgart: Fraunhofer.

HERNÁNDEZ-ASCANO, J., TIRADO VALENCIA, P.\& ARIZA-MONTES, A. (2016): "El concepto de innovación social: ámbitos, definiciones y alcances teóricos", CIRIEC-España, Revista de Economía Pública, Social y Cooperativa, 88, 165-199, DOI:10.7203/CIRIEC-E.88.8849.

HOWE, J. (2006): "The rise of crowdsourcing", Wired Magazine, 14(6), 1-5.

ICAA (Instituto de la Cinematografía y de las Artes Audiovisuales) (2016): Anuario de cine. Boletín informativo 2016. Recuperado de

http://www.mecd.gob.es/cultura/areas/cine/mc/anuario-cine/portada.html

JENKINS, H. (2008): Convergence Culture. La cultura de la convergencia de los medios de comunicación, Barcelona: Paidós.

JENKINS, H. (2009): Fans, blogueros y videojuegos, Barcelona: Paidós.

KLEEMAN, F., VOB, G.G. \& RIEDER, K. (2008): "Un(der)paid Innovators: The Commercial Utilization of Consumer Work through Crowdsourcing", Science, Technology and Innovation Studies, 4(1), 5-26, DOI:10.17877/DE290R-12790.

LAMBERT, T. \& SCHWIENBACHER, A. (2010): An Empirical Analysis of Crowdfunding. Recuperado de http://ssrn.com/abstract=1578175.

LAMELO, C. (2016): Televisión social y transmedia. Nuevos paradigmas de producción y consumo televisivo, Barcelona: Editorial UOC.

LANGE, A. (2001): "L'impact de la télévision numérique sur le marché des programmes audiovisuels". In: Peten, S., Sojcher, F. \& Thiec, Y. (Coords.), Cinéma, audiovisuel, nouveaux médias. La convergence: un enjeu européen? París: L'Harmattan.

LIN, M. \& VISWANATHAN, S. (2016): "Home bias in online investments: An empirical study of an online crowdfunding market", Management Science, 62(5), 1393-1414, DOI: 10.1287/mnsc.2015.2206.

NEIRA, E. (2015): La otra pantalla. Redes sociales, móviles y la nueva televisión, Barcelona: Editorial UOC.

RAMOS, J. \& GONZÁLEZ, B. (2016): "Crowdfunding and Employment: An Analysis of the Employment Effects of Crowdfunding in Spain". In: Brüntje, D. \& Gajda, O. (Eds.), Crowdfunding in Europe. State of the Art in Theory and Practice, Springer. DOI: 10.13140/RG.2.1.2720.1041. 
RIOUX, M. \& VERDUGO ULLOA, F. (2017): "Hacia una nueva gobernanza global de las industrias culturales en la era digital”. En: Albornoz, L.A. y García Leiva, M.T. (Eds.), El audiovisual en la era digital, Madrid: Cátedra, 43-70.

RODRÍGUEZ PRIETO, R. \& MARTÍNEZ CABEZUDO, F. (2016): Poder e Internet. Un análisis crítico de la red, Madrid: Cátedra.

ROIG TELO, A. (2010): "La participación como bien de consumo: una aproximación conceptual a las formas de implicación de los usuarios en proyectos audiovisuales colaborativos", Anàlisi: Quaderns de Comunicació i Cultura, 40, 101-114.

RUBIO, J.A, RIUS, J. \& MARTÍNEZ, S. (2014): El modelo español de financiación de las artes y la cultura en el contexto europeo, Fundación Alternativas y Fundación SGAE. Documento de trabajo $16 / 2014$.

SÁNCHEZ ROGER, M. (2015): "Crowdfunding y la economía de Internet", Análisis Financiero, 127, 112.

SCF (ASOCIACIÓN ESPAÑOLA DE CROWDFUNDING) (2014): Informe de la encuesta de la Asociación Española de Crowdfunding sobre plataformas españolas de Crowdfunding.

Recuperado de https://projectilblog.files.wordpress.com/2015/10/informe-de-la-encuesta-de-laasociaciocc81n-espancc83ola-de-crowdfunding.pdf

SGAE (SOCIEDAD GENERAL DE AUTORES Y EDITORES) (2017): Anuario SGAE de las artes escénicas, musicales y audiovisuales 2017. Recuperado de http://www.anuariossgae.com/anuario2017/home.html.

SOTO MOYA, M.M. (2017): "El acceso a la vivienda a través de aportaciones colectivas: especial referencia a sus consecuencias tributarias", CIRIEC-España, Revista Jurídica de Economía Social y Cooperativa, 31, 171-196.

SUROWIECKI, J. (2004): The wisdom of crowds. New York: Doubleday.

TOFFLER, A. (1980): La tercera ola, Barcelona: Plaza \& Janes.

TOMCZAK, A. \& BREM, A. (2013): "A conceptualized investment model of crowdfunding", Venture Capital: An International Journal of Entrepreneurial Finance, 15(4), 335-359, DOI: 10.1080/13691066.2013.847614.

VOORBRAAK, K.J.M. (2011): Crowdfunding for financing new ventures: consequences of the financial model on operational decisions, Eindhoven: Eindhoven University of Technology.

WENZLAFF, K., GUMPELMAIER, W. \& EISFELD-RESCHKE, J. (2012): Definition von Crowdfunding. Recuperado de http://www.ikosom.de/2012/06/11/definitionvoncrowdfunding-beta.

WOJCIECHOWSKI, A. (2009): "Models of charity donations and project funding in social networks", Computer Science, 5872, 454-463, DOI: 10.1007/978-3-642-05290-3_58. 
ZALLO, R. (2004): "Políticas culturales territoriales: una experiencia rica pero insuficiente". En: Bustamante, E. (Coord.), Comunicación y cultura en la era digital, Barcelona: Gedisa, 277-305.

ZALLO, R. (2017): "Políticas culturales y comunicativas para la diversidad de las expresiones culturales: una aproximación". En: Albornoz, L.A. y García Leiva, M.T. (Eds.), El audiovisual en la era digital, Madrid: Cátedra, 71-103.

\section{Legislación}

LEY 55/2007, de 28 de diciembre, del Cine, Boletín Oficial del Estado, Madrid, 29 de diciembre de 2007, núm. 312, pp. 53686-53701.

LEY 7/2010, de 31 de marzo, General de la Comunicación Audiovisual, Boletín Oficial del Estado, Madrid, 1 de abril de 2010, núm. 79, pp. 30157-30209. 